\title{
Relational Goods, Sociability, and Happiness
}

\author{
Leonardo Becchetti, Alessandra Pelloni and Fiammetta Rossetti*
}

\section{INTRODUCTION}

Man is a knot into which relationships are tied. Antoine de Saint-Exupéry, Flight to Arras, 1942.

Shared joy is a double joy; shared sorrow is half a sorrow, Swedish Proverb.

Someone to tell it to is one of the fundamental needs of human beings, Miles Franklin.

This paper empirically investigates the impact of relational goods on individual life satisfaction. By relational goods we indicate the affective/expressive, non instrumental, side of interpersonal relationships. Psychologists have long recognized relatedness as a key dimension of what it means to be humans ${ }^{1}$. However, in mainstream economics agents are mostly considered in isolation

* Leonardo Becchetti, Università di Roma Tor Vergata, Facoltà di Economia, Dipartimento di Economia e Istituzioni, Via Columbia 2, 00133 ROMA; tel: +39-06-72595719, fax: +39-062020500, e-mail: becchetti@economia.uniroma2.it. Alessandra Pelloni, Università di Roma Tor Vergata, Facoltà di Economia, Dipartimento di Studi Economici e Finanziari e Metodi Quantitativi, Via Columbia 200133 ROMA; tel: +39-06-72595908, fax: +39-06-2020500 e-mail: alessandra.pelloni@uniroma2.it. Fiammetta Rossetti, Università di Roma Tor Vergata, Facoltà di Economia, Dipartimento di Economia e Istituzioni, Via Columbia 2, 00133 ROMA; tel: +39-06-72595719, fax: +39-06-2020500, e-mail: fiammettarossetti81@yahoo.it. The paper is CEIS-University of Tor Vergata Working Paper n. 255. We thank Luigino Bruni, Andrew Clark, Rafael Di Tella, Benedetto Gui, Alois Stutzer and especially Bruno Frey for their comments and suggestions. The usual disclaimer applies.

1. According to Carr (2004) people with stronger social connections enjoy better physical and mental health as well as a lower risk of death. Developmental psychology research, on its turn, shows that interpersonal relations are established at the very onset of our life, even before a self-conscious subject of experience is constituted, see Stern (1985). The biological grounding of our social tendencies is confirmed by the recent discovery of mirror neurons which provide a direct internal experience, and therefore understanding, of another person's act, intention or emotion. When people use the expression 'I feel your pain' they may not realize how literally it could be true (Rizzolatti, Fogassi and Gallese, 2006). 
as they impersonally interact through markets, and consumption goods and leisure are assumed to be a 'sufficient statistics' of their utility. This solipsistic view of human nature has kept its predominance in the profession in spite of its many critics $^{2}$. Today it is further questioned by the recent upsurge of empirical studies on the determinants of self declared happiness, which show that an increasing income does not always lead to more subjective well being, the famous 'paradox of happiness' (Easterlin 1974).

The happiness research has studied the effects of a wide range of both economic and socio-demographic factors, from income to age and gender, from inflation and unemployment to health (Frey and Stutzer 2002a and b; Clark et al. 2006). However, among the personal relationships only marriage has been extensively considered (and found of paramount importance: see Stutzer and Frey 2006). Here we offer evidence on the impact on life satisfaction of a wider set of non instrumental social activities from volunteering, to spending time with friends, attending social gatherings and cultural and sports events.

Investigating the empirical nexus between these relational goods and happiness can have important policy implications. In traditional economics, we simply assume that someone's current utility depends on his current choiceset. The larger the choice-set, the better off the person. But this conclusion completely ignores the impact of one person's behaviour on the welfare of others when the interaction does not occur through markets. Such interdependencies are a basic part of human experience and we should expand our framework to take them into account when formulating and evaluating policies: the neglect of relatedness as a fundamental aspect of human life may severely limit economic analysis and curtail the validity of its policy prescriptions. For instance, if economic growth is obtained at the expense of the quality of the relational environment, the final outcome can be negative for happiness and this may reduce the political consensus for growth oriented policies $^{3}$. While obviously relational goods cannot be directly produced by the state, public action can avoid the growth-unhappiness paradox and promote personal interactions in many important ways, for instance by providing meeting places, by regulating shopping hours, by fixing the maximum work

2. Drawing casually from a very long list we can quote Sen (1977) who stresses sympathy and commitment as fundamental human drivers, Hirshleifer (1978) who contrasts the excessive emphasis in economics on 'man-thing' activities as opposed to 'man-man' activities and Akerlof and Kranton (2000) who propose to insert identity (self-image) in the utility function of agents.

3. This argument of course is not new. Polanyi (1944) argued that market economies tended to destroy the net of social relationships that kept society together. The market for labor induced people to move to where they could earn the most - creating strangers in strange lands. Human status rankings became the product of market forces rather than the result of social norms about justice. This had to be counterbalanced by strong public intervention. 
week, by supporting the arts and sports, by urban planning aimed at reducing commuting time etc. ${ }^{4}$.

Based on these premises, the paper provides an explicit empirical test on the importance of relational goods for individual happiness by testing jointly for the direct (intense human relationships increase happiness) and indirect (happier individuals have more intense relational life) causality link and by considering the impact of age, gender and education on this relationship. The paper is divided into five sections (introduction and conclusions included). In the next section we discuss some recent theoretical and empirical economic analysis of relational goods. In the third and fourth section we illustrate our descriptive evidence and econometric findings. The fifth section concludes.

\section{RELATIONAL GOODS: THEORETICAL BACKGROUND}

If the economy consisted in a complete set of perfect markets, personalised interaction among agents would be irrelevant for resource allocation. However in the real world agents have to meet to negotiate, exchange information, coordinate their actions inside organizations: much economic activity takes place not through market exchanges but through 'encounters' (Gui 2000). This interpersonal dimension of economic reality is still largely unexplored in economics notwithstanding the burgeoning literature on positional goods, social preferences, peer effects, social capital, etc.(see Gui and Sugden 2005 for a survey).

Here we contribute to this literature focusing our analysis on relational goods. Relational goods include companionship, emotional support, social approval, solidarity, a sense of belonging and of experiencing one's history, the desire to be loved or recognized by others etc. These goods are, on a smaller scale, produced by family relationships or friendships and, on a larger scale, in many kinds of social events (club or association meetings, live sport events, etc.). A general laughter during a comic movie, supporters' enthusiasm at the

4. Frey et al. (2005) discuss the life satisfaction approach as a way to learn about people's preferences for public goods by correlating the degree of public goods or 'bads' with individuals' reported subjective well-being and evaluating them directly in terms of life satisfaction, as well as relative to the effect of income. This novel approach is compared to revealed preference methods based on hedonic pricing and to stated preference methods based on contingent evaluation. What we are offering in this paper is in fact an application of the life satisfaction approach to the evaluation of a particular kind of public goods: our econometric method is particularly suited to minimize the problem of spurious correlations, while given the nature of our exercise, we don't have to make a choice as to which units are affected by the externality. 
stadium when their team scores a goal and applauses at a theatre are examples of relational goods produced on this larger scale.

To our knowledge, the economic analysis of relational goods was first proposed by Gui (1987) in studying the structures of a communitarian economy and by Ulhaner (1989) in explaining participation in political elections- an anomaly for rational choice models. These authors argue that relational goods are a specific kind of local public goods. They are public because, unlike conventional goods, they cannot be enjoyed by an isolated individual, but only jointly with some others. We can see the movie, the football match and the performance alone on TV but, in that case, the absence of other close co-participants will deprive ourselves of the public good aspect incorporated in such events.

They are local public goods because the collective entity consuming them is represented by a specific subset of agents in the economy. They are a specific kind of public goods, which should be better defined as anti-rival than as non rival, because their very same nature is based on the interpersonal sharing of them. As a consequence, participation to their consumption actually creates a positive externality on partners and contributes to the quality of the public good itself. In other terms, partners do not see non-rivalry and non-excludability (which may or may not be present) as negative elements which prevent them from exploiting all private benefits from the good, but as positive elements which augment its value (my satisfaction can be actually increased, or even crucially determined, by the fact that the other is also participating and taking pleasure to the extreme that congestion can increase utility!).

Another distinctive characteristics of relational goods is that they acquire value through sincerity or genuineness - which is impossible to buy, so they can be generated as a by product of some instrumental activity but not by making contracts for their supply. Friendship has to be its own reward and sympathy cannot be bought and sold without being transformed into something totally different ${ }^{5}$.

Gui and Sugden (2005) stress that relational goods can have important universal public benefits. For example, institutions which encourage people to trust others are classic examples of public goods. Such trustful atmosphere may

5. This does not mean that the opportunity of consuming relational goods cannot be bundled with other goods. For example, in selling packaged holidays for affinity groups, travel agents are in a sense selling the companionship of fellow-customers, while clubs are selling the companionship of fellow members. However this is possible because the non instrumentality of the companionship is guaranteed by the fact that the actual producers of the relational goods are not their sellers. There's of course no guarantee that such bundling will induce the welfare maximizing consumption of relational goods. 
depend not only on law but also on norms ${ }^{6}$, which are fostered by interpersonal relations (Putnam 2000) ${ }^{7}$.

As typically happens with public goods which cannot be exchanged trough markets, there are reasons to expect that relational goods will be underproduced and under-consumed.

People have to coordinate to produce a social event. The behaviour necessary for such coordination contributes to an interaction from which others also benefit, thereby generating an externality, a well known source of market failure. This creates the possibility of prisoner's dilemma-like traps of 'relational poverty', ensuing from individuals allocating too much time to the production of private goods.

Frey and Stutzer (2005) indicate additional relevant causes of under consumption of relational goods unrelated to the prisoner's dilemma in their production and to the difficulty of making contracts for their production. They stress that when people make decisions, they overvalue characteristics relating to consumption satisfying extrinsic desires (income and status) and underestimate the utility relating to consumption satisfying intrinsic needs (time spent with family and friends and on hobbies). Relational goods clearly fall in this second category of consumption.

The authors list many sources leading individuals to underestimate future utility from intrinsic attributes, compared to extrinsic attributes of goods and activities. First, there is evidence of little or no adaptation for goods and activities characterized by intrinsic attributes, and of strong adaptation for those characterized by extrinsic attributes. Since there is evidence that people tend to underestimate adaptation we can deduce that people underestimate benefits from extrinsic attributes with respect to benefits from intrinsic ones. Moreover when individuals choose what goods to consume they have to resort to their experiences from the past. What counts as 'more memorable' tends to be the most intense moment (peak) and the most recent moment (end) of an emotional occurrence (Kahneman 2003). Frey and Stutzer (2005) propose that, while extrinsic attributes create mostly peak emotions, intrinsic attributes give rise to longer-term positive experiences. Under-consumption of intrinsic attributes follows by this route.

Other possible causes of under-consumption of intrinsic attributes are grounded in our culture. Individuals have a strong urge to justify their

6. Habermas' (1990) and Apel's (1990) discourse ethics is based on the idea that normative validity cannot be understood as separate from the argumentative procedures used in everyday practice to validate the norms that regulate social interactions. Moral principles are extracted from the necessary preliminary conditions of communication on validity claims (e.g. the condition that no force except that of the better argument is used).

7. We notice however that the econometric techniques we use are unable to capture these more universal benefits of relational goods. 
decisions, both to themselves and to other persons. But in western societies it is much easier to provide rational justifications for extrinsic rather than for intrinsic characteristics. Finally, relatively higher misprediction in intrinsic than in extrinsic aspects is also induced by market practices such as advertising, which of course are mainly directed towards marketed goods .

Summing up, these theoretical analyses of relational goods converge in predicting that, in general, consumption of relational goods will be inefficiently low. The hypothesis we test empirically is that those individuals who consume more relational goods, i.e. who are have been more successful in solving the problems related to the reduced incentives and the cognitive problems hindering their production, will be on average better off than those who have been less successful in doing so ${ }^{8}$.

Moreover our work can be useful in studying the 'distributional' consequences of policies producing changes in patterns of relational goods consumption. If there were a decrease in the frequency and intensity of consumption of relational goods would some people be systematically lose out? Are relational goods particularly important for some groups?

To provide an idea of how our contribution relates (and is original with respect) to past work in this field, consider Gui and Sugden (2005) when they argue that the essence of the debate on the role of relational goods in economics revolves around two main questions: are relationships an important input of (or output affected by) economic activity which is neglected in traditional analyses? ${ }^{9}$ Do human relationships (outside the economic sphere) directly affect individual wellbeing beyond their impact on economic outcomes? Our paper essentially aims to provide an answer to the second question. More specifically, given the features of some of our relational variables described in more detail in the next section (attendance at social gathering, attendance at cultural events), the aspect of relational goods we are going to test is the hypothesis that interpersonal relations can enhance life satisfaction even though subjects are quite passive and do not device any particular coordinated joint action beyond the decision of attending the same event.

In this perspective we are close to the 'fellow feeling' hypothesis of Adam Smith, rediscovered by Sugden's (2002), according to which individuals'

8. Independent evidence corroborating this analysis is that people with material or extrinsic life goals report lower self-esteem and life satisfaction than people with intrinsic life goals (e.g. Kasser 2002; Sirgy 1997).

9. Gui and Sugden (2005) divide this question into the following subtopics providing evidence on each of them: i) Economic choices can affect interpersonal relations outside the economic sphere. ii) Interpersonal relations outside the economic sphere can affect economic performance. iii) Interpersonal relations inside the economic sphere can affect economic performance. iv) Interpersonal relations inside the economic sphere can affect well-being. 
mutual awareness of a common sentiment is in itself a source of pleasure for them.

Other papers close to our approach are those of Schiff (2002) showing that, even though migrant workers often earn greater income than those who stay behind, their quality of life suffers from poor interpersonal relations, and of Diwan (2000) illustrating that the characteristics of the networks of personal relations in which people are involved have significant welfare effects. Bruni and Stanca (2008) offer cross-sectional evidence of a positive effect of indicators of relational goods on life satisfaction. Another related paper is Meier and Stutzer (2008) who work on the same data set we use (the GSOEP) but limit their analysis to volunteering: they find robust evidence that volunteers are more satisfied with their life than non-volunteers, and consider this result as supporting the view that altruism promotes the wellbeing of altruists.

A problem with this evidence is that of the endogeneity of regressors and inverse causality, issues for which it is easier to find a solution working with panel data as we do and adopting an estimation approach which jointly tests for direct and inverse causality between happiness and relational goods.

\section{CONSTRUCTION OF DATABASE AND VARIABLES}

In order to test the importance of human relationships for individual happiness we work on one of the richest databases available (German Socio Economic Panel: GSOEP) which contains both cross-sectional and longitudinal information (extracted from 21 waves going from 1984 to 2004) on many variables (including self declared happiness and indicators of relational life) for a large sample of individuals.

In the original GSOEP dataset we find the following five indicators measuring time dedicated to the production of relational goods: i) 'attend social gatherings'; ii) 'attend cultural events'; iii) 'participate in sports'; iv) 'perform volunteer work'; v) 'attend church or religious events'. Each of these variables can take values from 1 to 4 , depending on how much time is devoted to the specific relational activity $(1=$ Never, $2=$ Less Frequently, $3=$ Every Month and $4=$ Every Week).

Do all these activities produce relational goods as we defined them in the previous section? Social gatherings are expected to generate strong 'fellow feelings' which strengthen ties among participants. Any individual who decides to participate creates a positive externality for the other participants: being in a larger number gives a feeling of community and empowerment, provides a confirmation which reinforces the decision to participate to the gatherings and increases their enjoyment. Cultural events have similar features even though the activity by the participants is much weaker (the event is produced 
regardless, and even with very few participants. However, high participation may increase the value of the good). With regard to the third relational variable, active (athletes) and passive (bystanders) participants in sporting events produce and consume local public goods not just in the case of teams but also of individual sports, at least to the extent in which they take place in a normally competitive environment in which the presence of other competitors is required ${ }^{10}$. The communal dimension is essential in church or religious events.

Voluntary work is generally performed in groups and participation has also the effect of reinforcing motivation and create solidarity not only among volunteers (i.e. a work camp or social service performed by members of an association), but also between the volunteers and the beneficiaries of the work undertaken. The 'fellow feeling' argument therefore applies also here.

We build a Relational Time Index' (from now on RTI) by averaging values for these five variables for each respondent. ${ }^{11}$ We built the RTI index in this way for two main reasons.

First, we want a synthetic indicator on the relational time of individuals which goes beyond the information given by a single variable.

Second, the synthetic indicator helps us to solve in part the problem of missing data. In fact, none of the above five variables features in all of the 21 waves of our dataset. We calculate the RTI index on the basis of non missing relational variables for each individual-year in order to have a higher number of observations and to cover more years. However, for the sake of completeness, we present results for the selected specifications with both the aggregate RTI index and its individual components as separate regressors.

Another variable related to human relationships and one traditionally considered in the empirical literature is relative income. Several papers argue that positional status and the ratio between one's own and the reference group income significantly affect life satisfaction (see, among others, Duesenberry 1949, Frank 2005 and Layard 2005). From the empirical point of view the problem is obviously the definition of the reference group. A benchmark paper

10. In the case of soccer it has frequently happened that organised fans have used (i.e., by enacting or threatening to enact a supporter 'strike') their capacity to coordinate and produce the very public good, which contributes to the success of their team, in order to increase their bargaining power in the division of team net sales

11. We do this since survey answers do not allow us to infer exactly a per month or per week frequency in presence of the 'less frequently' response. Given the more than proportional increase in intensity between 'each month' and 'each week', our unweighted average flattens high intensity responses and may be conceived as a sort of log transform of the real unmeasurable frequency of relational activities. A robustness check in which we compute presumed actual frequencies on the basis of qualitative responses (and, more specifically, one every two months for the 'less frequently' answer) has been performed. Results are substantially unchanged and available from the authors upon request. 
on this issue is Ferrer-i-Carbonell (2005), who, working on the same database that we use, calculates relative income as the average income of individuals being part of the same age, education and (West and East Germany) regional subgroups. In a similar way, we divide observations into classes according to gender, age, region and education. For age and education we consider 3-year classes. Since age in our sample goes from 19 to 99 years we have 27 classes, whilst there are 4 classes of education (ranging from 7 to 18 years in our sample). All this considered, the combination of our criteria leads to the definition of $2 * 2 * 27 * 4$ classes. We therefore build the reference household income of each individual by just taking the mean of the real household income group to which he belongs.

The other regressors included in our estimates (age, gender, education, marital and employment status, health) are standard in the literature. In order to describe the marital status of the interviewed individuals we jointly consider status variables (married, single, separated, divorced, widowed) and shocks identifying transition from one status to another (marriage, separation and partner's death). For the employment condition we follow the same approach and consider as status variables full time, regular part-time and marginal irregular part-time employment, while also measuring shocks related to loosing employment or getting new jobs.

\section{DESCRIPTIVE FINDINGS}

Life satisfaction is typically a measure of limited variation across years for the same individual. A preliminary inspection of our data shows that the $0-10$ self declared life satisfaction variable exhibits year to year persistence in the same happiness level which is weaker at low levels (below 20 percent when the previous year self declared happiness is below 5) and highest at level 8 (48.16 percent $)^{12}$.

All relational activity indicators appear positively associated with self declared happiness. The index of attendance at social gatherings varies between 2.58 to 3.26 (that is, from less to more than monthly frequency) when moving from the lowest to the highest life satisfaction value, attendance at cultural events from 1.28 to 1.69 , participation in sports from 1.49 to 2.03 , undertaking volunteer work from 1.21 to 2.03 and attendance at church or religious events from 1.45 to 1.99 .

With regard to the marital status relational variables we observe that 62 percent year-observations correspond to married individuals (singles status

12. Tables on descriptive findings are omitted for reasons of space and available from the authors upon request. 
equals 23 percent and divorced 5.5 percent). Episodes of marriage and separation cover respectively 1.9 and 1.4 percent of our observations.

These variables exhibit well defined variations across different levels of life satisfaction. The share of married respondents is 51 percent at (life satisfaction) level 1 and increases to 65 percent at level 10. Separated (divorced) are represented by 6 percent (11 percent) among the least satisfied and fall to 2 percent ( 4 percent) among the most satisfied. 5 percent of the least satisfied have experienced episodes of separation in the interview year against only 1 percent of the most satisfied.

With regard to our aggregate index of relational goods we find that its value is always higher for positive changes in happiness than for negative changes of the same amount (i.e. 1.76 (1.63) for those with an increase (decrease) of happiness of seven points). If we look at index components we observe that this finding is generally confirmed when we consider attendance at social gatherings and cultural events, but not attendance at church or religious events.

\section{ECONOMETRIC FINDINGS}

Since our dependent variable is discrete qualitative and takes values from 0 to 10 , the standard approach is an ordered probit estimate. However, given the extended range of our life satisfaction measure, the same dependent variable has sometimes been approximated in the literature to a continuous variable so that OLS and panel fixed effect models have both been estimated (Stutzer and Frey 2006). We opt for the fixed effect approach which allows easier interpretation of magnitude effects after checking that our results are substantially analogous under the two alternative methods. ${ }^{13}$ We select two different specifications. In the first we use the aggregate relational good variable and dispose of approximately 80,000 observations. In the second we replace this composite index with all its individual components. This last choice necessitates that we work only with those waves in which all individual components are non missing and therefore reduces the sample to around 30,000 observations. More specifically, in terms of sample periods, the first specification includes also observations from the 1980s, while the second only those from the 1990s.

The index of relational goods has positive and significant coefficients both in the level and in the first difference equation (column 1, Tables 1 and 2). We therefore do not reject the hypothesis that relational goods affect happiness.

The level equation tells us that higher intensity of relational life is positively related to higher level of self declared happiness, net of the effects of the other

\footnotetext{
13. Results are omitted for reasons of space and available from the authors upon request.
} 


\section{RELATIONAL GOODS, SOCIABILITY, AND HAPPINESS}

\section{Table 1}

The Determinants of Life Satisfaction: Level Estimates (fixed effects)

Age

Male

Germany

Education In Years

Married

Separated

Single

Divorced

$\boldsymbol{R T I}$ (aggregate relational time index)

Attend Social Gatherings

Attend Cultural Events

Participate In Sports

Perform Volunteer Work

Full Time Employment

Regular Part Time Employment

Ln (Real Household Income)

In (Reference Household Income)

Nr. of Persons In the Household

Nr. of Annual Doctor Visits

Constant Term

$$
\begin{gathered}
-0.003 \\
(-4.38)^{* *} \\
-0.079 \\
(-5.51)^{* *} \\
-0.056 \\
(-2.41)^{* *} \\
0.007 \\
(1.88)^{*} \\
0.160 \\
(5.31)^{* *} \\
-0.049 \\
(-1.06) \\
-0.007 \\
(-0.20) \\
-0.360 \\
(-8.62)^{* *} \\
0.571 \\
(51.05)^{* *}
\end{gathered}
$$

$(-3.92)^{* *}$

0.015

$(0.50)$

$-0.001$

$(-0.32)$

0.167

$(4.68)^{* *}$

$-0.009$

$(-0.18)$

$-0.029$

$(-0.67)$

$-0.390$

$(-7.70)^{* *}$

0.262

$(27.29)^{* * *}$

0.134

$(12.36)^{* *}$

0.096

$(13.91)^{* *}$

0.081

$(9.51)^{* *}$

0.124

$(6.73)^{* *}$

0.068

$(2.17)^{*}$

0.547

$(31.09)^{* *}$

$-1.158$

$(-13.87)^{* *}$

$-0.062$

$(-8.96)^{* *}$

$-0.014$

$(-31.35)^{* *}$

10.831

$(16.57)^{* *}$

$(23.06)^{*}$

59,550

274.74

3.14

79,846

474.79

4.10

F-Test/Log Likelihood

F-Test fixed effects

Variable legend. Happiness: 0-10 response on individual's overall life satisfaction, Age: respondent's age, Male: gender (0/1) dummy, Germany: dummy for German residents, Education in Years: number of education years, Married, Separated, Single and Divorced: marital status (0/1) dummies, Full time employment and Regular part time employment, Ln (Real Household income): $\log$ of the real household income, Ln (Reference household income): $\log$ of the respondent's reference group income (see section III). Nr. of persons in the household and $N r$. of annual doctor visits: the number of people living in the respondent's household and the number of respondent's visit to the doctor in the last year, respectively. RTI: relational time index (for details on its construction see section III). In the estimate presented in column 2 the aggregate RTI index is replaced by its individual components. T-stats in round brackets

**99 percent statistical significance.

* 95 percent statistical significance. 


\section{LEONARDO BECCHETTI/ALESSANDRA PELLONI/FIAMMETTA ROSSETTI}

\section{Table 2}

The Determinants of Life Satisfaction: Differenced Estimates (fixed effects)

\begin{tabular}{|c|c|c|}
\hline Age & $\begin{array}{c}0.001 \\
(1.26)\end{array}$ & $\begin{array}{c}0.006 \\
(1.77)^{*}\end{array}$ \\
\hline Male & -0.032 & -0.032 \\
\hline & $(-1.68)^{*}$ & $(-0.82)$ \\
\hline Germany & 0.090 & 0.113 \\
\hline & $(3.39)^{* *}$ & $(2.18)^{*}$ \\
\hline Education In Years & 0.001 & -0.012 \\
\hline & $(0.32)$ & $(-1.57)$ \\
\hline Married & -0.078 & -0.193 \\
\hline & $(-1.86)^{*}$ & $(-1.89)^{*}$ \\
\hline Separated & -0.097 & -0.102 \\
\hline & $(-1.66)^{*}$ & $(-0.86)$ \\
\hline Single & -0.039 & -0.012 \\
\hline & $(-0.76)$ & $(-0.10)$ \\
\hline Divorced & 0.036 & 0.163 \\
\hline & $(0.62)$ & $(1.00)$ \\
\hline$\Delta R T I$ & $\begin{array}{l}0.132 \\
(7.71)^{* *}\end{array}$ & \\
\hline AAttend Social Gatherings & & $\begin{array}{l}0.100 \\
(5.34)^{* *}\end{array}$ \\
\hline AAttend Cultural Events & & $\begin{array}{c}0.035 \\
(1.65)^{*}\end{array}$ \\
\hline AParticipate In Sports & & $\begin{array}{r}0.019 \\
(1.18)\end{array}$ \\
\hline APerform Volunteer Work & & $\begin{array}{r}0.019 \\
(0.91)\end{array}$ \\
\hline Full Time Employment & $\begin{array}{l}0.094 \\
(4.54)^{* *}\end{array}$ & $\begin{array}{l}0.142 \\
(3.46)^{* *}\end{array}$ \\
\hline Regular Part Time Employment & $\begin{array}{c}0.053 \\
(1.52)\end{array}$ & $\begin{array}{c}0.039 \\
(0.54)\end{array}$ \\
\hline d In (Real Household Income) & $\begin{array}{c}0.336 \\
(11.96)^{* *}\end{array}$ & $\begin{array}{c}0.375 \\
(7.78)^{* *}\end{array}$ \\
\hline d In (Reference Household Income) & $\begin{array}{c}-0.711 \\
(-2.29)^{* *}\end{array}$ & $\begin{array}{l}-1.131 \\
(-1.71)^{*}\end{array}$ \\
\hline Nr. of Persons In the Household & $\begin{array}{l}-0.006 \\
(-0.83)\end{array}$ & $\begin{array}{l}-0.020 \\
(-1.49)\end{array}$ \\
\hline Nr. of Annual Doctor Visits & $\begin{array}{c}-0.003 \\
(-6.91)^{* *}\end{array}$ & $\begin{array}{c}-0.004 \\
(-3.63)^{* *}\end{array}$ \\
\hline Constant Term & $\begin{array}{l}-0.128 \\
(-1.60)\end{array}$ & $\begin{array}{c}-0.016 \\
(-0.09)\end{array}$ \\
\hline Observations & 43,614 & 14,568 \\
\hline F-Test/Log Likelihood & 21.57 & 9.04 \\
\hline F-Test fixed effects & 0.63 & 0.62 \\
\hline
\end{tabular}

Varaible legend. $\Delta$ Happiness: one year difference in the $0-10$ response on individual's overall life satisfaction, $\Delta L n$ (Real Household income): one year difference in the log of the Real household income, $\Delta \operatorname{Ln}$ (Reference household income): one year difference in the log of our measure of the respondent's reference group income, $\triangle R T I$ : one year difference in the RTI index. The other variables are described in Table 2 legend. In the estimate presented in column $2 \triangle R T I$ is replaced by the one year changes of its individual components. T-stats in round brackets

**99 percent statistical significance.

*95 percent statistical significance 
variables (Table 1). In addition, the first difference equation adds that positive (negative) changes in relational life are significantly associated to positive (negative) changes in life satisfaction (Table 2).

When we disaggregate the index into its different components in the second specification we observe that all components remain significant in level estimates (column 2, Tables 1 and 2). In terms of coefficient magnitude attendance at social gatherings has double the weight with respect to participation in cultural events and more than that with respect to the other two indicators (sport activities and voluntary work). Attendance at social gatherings is also the only strongly significant variable in the equation in first differences and its coefficient is here three times larger than that of participation to cultural events. Notice that of all the activities we include in our index, social gathering is the most purely relational so it is not surprising that it turns out to be the most efficient generator of pleasurable 'correspondence of sentiments'.

The negative sign of the reference group income in both level and first difference estimates confirms that a higher income of our peers is associated with lower happiness levels and a positive change in peers' income levels is significantly related to a reduction of our own life satisfaction. The significance of the relative income effect confirms the ambivalence of human relationships. In our life with others we enjoy the positive effects of sociability, whilst simultaneously suffering from interpersonal comparisons when they are unfavourable to us.

When we consider marital status variables, traditionally capturing other dimensions of our relational life, we observe that marriage is positively related to happiness while the 'separated' status attracts a negative and significant coefficient when we omit data from the 1980s and slightly less so when they are included. The divorced status coefficient is always negative and significant consistently with what is traditionally found in the empirical literature.

The effect of full time employment is more stable and positive across all estimates. This implies that it is robust across years and independent of individual fixed effects. The same story can be told for the positive effect of real household income and the negative effect of relative income. The effect of our health proxy is also strong and robust.

To evaluate the economic significance of these effects, and to compare them across variables with heterogeneous scales, we calculate the impact of one standard deviation change of the regressor in terms of percent of a standard deviation change of the dependent variable.

To make an example, the standard deviation of Age is 17.155. Hence, if we increase Age by one standard deviation, the predicted effect on happiness (coefficient magnitudes of column 1 in Table 1$)$ is $(17.155) *(-0.003)$ $=-0.052$. The standard deviation of Satisfaction With Life Today is 1.850 , thus, an increase of one standard deviation in Age causes a decrease of -0.052 / $1.850=-0.028$ of a standard deviation in happiness. 
Following this approach, we observe that the most relevant variable, in terms of economic significance (magnitude of its effect), is the relational index (RTI), followed by the log of real household income and the number of annual doctor visits. An increase in RTI of one (of its own) standard deviations would increase happiness by 0.195 of its standard deviation. This falls to 0.164 and -0.131 for one standard deviation increase in the log of Real Household Income and in the number of Annual Doctor Visits respectively.

\section{First Difference and Panel Vector Autoregression (VAR) Estimates}

There is however a serious problem of endogeneity in happiness estimates. As is well known, marriage may positively contribute to happiness but higher life satisfaction positively affects the probability of getting married (Stutzer and Frey 2006). In the same way, even though we expect that a job and a higher income may increase life satisfaction, we also know that happier people are more likely to find jobs and earn more amongst other effects (Clark et al. 2006).

Frey and Stutzer (2002a) correctly argue that panel data eliminate heterogeneity caused by those time invariant individual traits inherited from childhood or birth. Clark et al. (2006) object however that part of the endogeneity in the happiness-income nexus may be generated by time varying factors, such as changes in health, which may lead to both higher happiness and income.

In some papers the problem has been partially solved by exploiting 'quasinatural experiments' or external events which have been considered as determining exogenous changes in income (lottery wins, aggregate changes in real income after transition in Russia or reunification in Germany respectively, see Gardner and Oswald 2004, Frijters et al. 2004a, 2004b and 2006, Meier and Stutzer 2008).

Here we follow two different approaches to control for endogeneity. First, we reestimate the model in first differences and, second, we estimate a VAR system in which instrumental variables can be used and where direct and reverse causality can be jointly taken into account.

The first approach is only a partial response to the problem. We may rely on it if we believe that changes in happiness will slowly affect changes in our regressors, while changes in our regressors instantaneously affect changes in happiness. For example, it is much easier to believe that an increase in real household income generates an increase in happiness in the same year than that an (exogenous) increase in happiness of an interviewed individual has an immediate positive effect on his household earning capacity. 
Our first differenced estimate in Table 2 shows that the variables which gave the most robust findings in level estimates also pass this test. Changes in relational activities, household income, relative income and health are significantly correlated in the expected direction with changes in self declared happiness. Such findings are invariant to the three estimation approaches followed (pooled OLS, panel fixed effects, ordered probit) ${ }^{14}$.

However, if we are strongly concerned about biunivocal causality and endogeneity, and not fully convinced by first differenced estimates, the Generalised Method of Moments (GMM) panel vector autoregression (VAR) approach $^{15}$ is the most suitable one under the assumption that our $0-10$ variable can be approximated by a continuous one. The advantage with such an approach is that we can estimate a system in which we jointly test whether production of relational goods causes happiness and viceversa.

The base GMM VAR model has two equations. In the first the current level of life satisfaction is regressed on lagged levels of life satisfaction and lagged levels of the index of relational goods. In the second equation the current level of the relational good index is regressed on its lagged values and on the lagged values of life satisfaction. Fixed effects are also included as regressors in both equations.

Given the model it is possible to test the following hypotheses:

\section{$H_{O A}$ : the time invested in relational goods does not Granger-cause life satisfaction.}

This occurs if the sum of the coefficients of the lagged relational good index is not significantly different from zero in the first equation. That is, if (lagged values of) the relational good index do not significantly affect life satisfaction, net of the impact of the lagged values of the latter.

\section{$H_{O B}$ : life satisfaction does not Granger-cause the time invested in relational goods.}

This occurs if the sum of the coefficients of lagged life satisfaction is not significantly different from zero in the second equation. That is, if (lagged values of) life satisfaction do not significantly affect investment in relational goods, net of the impact of the lagged values of the latter.

The crucial point of this approach is that the two hypotheses (direct and inverse causality between the two variables) are jointly tested.

14. Fixed effects and ordered probit estimates are omitted for reasons of space and available upon request.

15. For details on this approach see Arellano and Bond (1991) and Arellano and Bover (1995). 
After testing the two hypotheses on the overall sample we do the same on splits based on sample period, gender, education, nationality and age. Our goal is to check when, where and for whom the nexus between relational goods and life satisfaction is stronger.

Table 3 tells us that, when we estimate the system on the overall sample, both null hypotheses are rejected since the time invested in relational goods Granger causes happiness and viceversa. The result is robust to several (age, education, gender and nationality) sub-sample splits of the two variable model $^{16}$, and also to the introduction of additional variables (health and income) in a three (four) equation system in which the impact of relational goods on happiness is evaluated net of i) the reverse causality links between the two variables, ii) the impact of health and iii) the two added regressors ${ }^{17}$.

Evidence from subsample splits, confirmed under standard augmented model specifications, shows that the relational good-happiness nexus (net of the reverse causality phenomenon) is stronger for females (the coefficient of the lagged RTI index on life satisfaction is .67 against .46), for older (.69 against .46) and less educated people (.61 against .36) and for East than for West Germans (.66 against .56). The gender result appears in accordance with the generally accepted idea that women tend to be more empathetic ${ }^{18}$, and are 'more avid social capitalists', to borrow Putnam's expression ${ }^{19}$. Age and education findings may be interpreted in the light of the reduced opportunities for other activities contributing to happiness in the lives of the old and the less educated $^{20}$. This means human relationships will play a bigger role in their lives. Indeed the association between social relationships and lower mortality has

16. We also divided the sample in two equal time periods but we do not find significant differences in the effect of relational goods on happiness between such periods. Results are omitted for reasons of space and available from the authors upon request.

17. These findings are omitted for reasons of space and available from the authors upon request.

18. Stronger magnetoencephalographic responses related to the mirror neuron system have been recorded in women compared to men (see Cheng et al. 2006).

19. Nelson (1996) argues that economists' overwhelming reliance on models of individual choice reflect masculinist biases rooted in Cartesian divisions between rationality and embodiment and that the discipline should not be concerned merely with goods and services traded in the market but with all the necessities and conveniences that sustain life. She writes 'The central model of economics views people as individuals, and each individual as self-interested, autonomous, rational, and free to choose among different actions. Logically, the converse of this would be a view of people as linked to others and concerned about their welfare-people who are dependent, emotional, and subject to decisions made by others or influences from the social or natural environment. Not just coincidentally, all the characteristics in the first list have been, in modern Western and English-speaking cultures, associated with stereotypical masculinity, while all those in the latter list are associated with stereotypical femininity.'

20. This finding of the lower importance of the relationships for the more educated would have not surprised Aristotle who judges the contemplative life the most self-sufficient among the human activities which can be included in the plan for the good life (see Nussbaum 2001, chap. 12). 


\section{RELATIONAL GOODS, SOCIABILITY, AND HAPPINESS}

\section{Table 3}

The Determinants of Life Satisfaction and Relational Life: GMM Panel VAR with Sample Splits

\begin{tabular}{|c|c|c|c|}
\hline Sample split & & $\begin{array}{l}\text { Satisfaction with } \\
\text { Life Today }\end{array}$ & $\begin{array}{l}\text { Relational Time } \\
\text { Index }\end{array}$ \\
\hline Overall sample & $\begin{array}{l}\text { Lag Satisfaction with Life Today } \\
\text { Lag RTI }\end{array}$ & $\begin{array}{c}0.386 \\
(89.58)^{* *} \\
0.553 \\
(38.88)^{* *}\end{array}$ & $\begin{array}{c}0.030 \\
(21.87)^{* *} \\
0.157 \\
(33.01)^{* *}\end{array}$ \\
\hline Male & $\begin{array}{l}\text { Lag Satisfaction with Life Today } \\
\text { Lag RTI }\end{array}$ & $\begin{array}{c}0.375 \\
(62.88)^{* *} \\
0.460 \\
(25.64)^{* *}\end{array}$ & $\begin{array}{c}0.046 \\
(23.33)^{* *} \\
0.203 \\
(32.61)^{* *}\end{array}$ \\
\hline Female & $\begin{array}{l}\text { Lag Satisfaction with Life Today } \\
\text { Lag RTI }\end{array}$ & $\begin{array}{c}0.400 \\
(63.46)^{* *} \\
0.669 \\
(29.21)^{* *}\end{array}$ & $\begin{array}{l}0.014 \\
(7.18)^{* *} \\
0.098 \\
(13.26)^{* *}\end{array}$ \\
\hline Germany & $\begin{array}{l}\text { Lag Satisfaction with Life Today } \\
\text { Lag RTI }\end{array}$ & $\begin{array}{c}0.392 \\
(72.90)^{* *} \\
0.573 \\
(32.75)^{* *}\end{array}$ & $\begin{array}{c}0.029 \\
(17.49)^{* *} \\
0.176 \\
(30.03)^{* *}\end{array}$ \\
\hline Not Germany & $\begin{array}{l}\text { Lag Satisfaction with Life Today } \\
\text { Lag RTI }\end{array}$ & $\begin{array}{c}0.357 \\
(38.44)^{* *} \\
0.483 \\
(14.68)^{* *}\end{array}$ & $\begin{array}{l}0.025 \\
(9.12)^{* *} \\
0.131 \\
(12.92)^{* *}\end{array}$ \\
\hline West Germany & $\begin{array}{l}\text { Lag Satisfaction with Life Today } \\
\text { Lag RTI }\end{array}$ & $\begin{array}{c}0.402 \\
(71.18)^{* *} \\
0.560 \\
(30.02)^{* *}\end{array}$ & $\begin{array}{c}0.029 \\
(16.70)^{* *} \\
0.195 \\
(31.41)^{* *}\end{array}$ \\
\hline East Germany & $\begin{array}{l}\text { Lag Satisfaction with Life Today } \\
\text { Lag RTI }\end{array}$ & $\begin{array}{c}0.360 \\
(21.42)^{* *} \\
0.664 \\
(11.52)^{* *}\end{array}$ & $\begin{array}{l}0.022 \\
(4.15)^{* *} \\
0.062 \\
(3.33)^{* *}\end{array}$ \\
\hline Education In Years $\leq 12$ & $\begin{array}{l}\text { Lag Satisfaction with Life Today } \\
\text { Lag RTI }\end{array}$ & $\begin{array}{l}0.387 \\
(82.02)^{* *} \\
0.608 \\
(37.42)^{* *}\end{array}$ & $\begin{array}{l}0.026 \\
(18.11)^{* *} \\
0.139 \\
(26.45)^{* *}\end{array}$ \\
\hline Education In Years $\leq 12$ & $\begin{array}{l}\text { Lag Satisfaction with Life Today } \\
\text { Lag RTI }\end{array}$ & $\begin{array}{c}0.374 \\
(34.89)^{* *} \\
0.358 \\
(12.06)^{* *}\end{array}$ & $\begin{array}{c}0.055 \\
(12.81)^{* *} \\
0.218 \\
(19.74)^{* *}\end{array}$ \\
\hline $\operatorname{Age} \leq 43$ & $\begin{array}{l}\text { Lag Satisfaction with Life Today } \\
\text { Lag RTI }\end{array}$ & $\begin{array}{c}0.368 \\
(60.58)^{* *} \\
0.465 \\
(24.46)^{* *}\end{array}$ & $\begin{array}{l}0.043 \\
(21.35)^{* *} \\
0.213 \\
(32.87)^{* *}\end{array}$ \\
\hline Age $>43$ & $\begin{array}{l}\text { Lag Satisfaction with Life Today } \\
\text { Lag RTI }\end{array}$ & $\begin{array}{c}0.413 \\
(64.40)^{* *} \\
0.689 \\
(30.71)^{* *}\end{array}$ & $\begin{array}{l}0.016 \\
(8.45)^{* *} \\
0.083 \\
(11.36)^{* *}\end{array}$ \\
\hline
\end{tabular}

Note: the Table reports coefficients and t-stats (in parenthesis) relative to the effect of (row) regressors on (third and fourth column) dependent variables in GMM panel VAR system.

** 99 percent statistical significance. 
been well documented ${ }^{21}$. The stronger coefficient in the East German sample may depend from the shock related to the fall of the old system of relational ties and the transition to a more competitive environment. Such result is however weaker and not always robust in the augmented model specifications ${ }^{22}$.

\section{CONCLUSIONS}

Many recent approaches in the social sciences emphasize the importance of relational aspects in human identity.

Empirical studies on the determinants of life satisfaction give us a unique opportunity for testing the proposition of the relevance of the social dimension in human life. Our findings do not reject the hypothesis that this dimension is highly significant in at least two respects. On the one side, relative affluence of our 'reference group' (those we consider our peers) is shown to have significant and negative effects on happiness. On the other side, time spent in producing and consuming relational goods is shown to generate significant and positive effects on life satisfaction. We also show that relational goods have a bigger impact on the subjective wellbeing of women, the older and the less educated. This finding can be useful in designing and evaluating public policies with a direct or indirect effect on the quality and quantity of relational goods.

In our work we pay particular attention to control for endogeneity and reverse causality. If good relational life can positively affect individual happiness it is also reasonable to assume that life satisfaction may affect people's decisions to invest in relationships. Beyond looking at the relationships not just in levels but also in first differences, we explicitly try to disentangle the two causality directions in a GMM panel VAR system in which both of them are jointly tested and estimated.

We show that the two null hypotheses of the insignificance of the effects of time invested in relational life on happiness and of happiness on time invested in relational life are rejected. Granger causality in both directions is supported by our findings in both the overall sample and in gender, age, education and nationality splits.

The robustness of the relational goods-happiness nexus evidenced by our results seems to confirm that the anthropological assumptions in standard economic models should be broadened to take into better account the social

21. Rasulo, Christensen and Tomassini (2005) show that the frequency of interactions with children, relatives, and friends significantly lowers the risk of dying in late life. This by itself could explain why elder people care more about relationships.

22. These findings are confirmed when we estimate in sample splits the equation in differences of Table 3 . Results are omitted for reasons of space and available upon request. 
domain and that policymakers should pay attention to potential unintended effects of policy measures on the social fabric of contemporary societies.

Extending the framework of economic analysis to interpersonal relations is ridden with problems of conceptualization and measurement. However we hope we have contributed to prove that it is worthwhile trying to solve these problems: an economic culture ignoring the hidden costs and benefits of our choices for the social environment can mislead both individual and collective actions.

\section{REFERENCES}

Akerlof, George A. and Rachel E. Kranton (2000). Economics and Identity, The Quarterly Journal of Economics. 115(3): 715-753.

Apel, Karl O. (1990). Is the Ethics of the Ideal Communication Community a Utopia? On the Relationship between Ethics, Utopia, and the Critique of Utopia, in: Seyla Benhabib and Fred R. Dallmayr (eds.), The Communicative Ethics Controversy. Cambridge (Mass): MIT Press: 23-59.

Arellano, Manuel and Stephen Bond (1991). Some Tests of Specification for Panel Data: Monte Carlo Evidence and an Application to Employment Fluctuations, Review of Economic Studies. 58: 277-297.

Arellano, Manuel and Olympia Bover (1995). Another Look at the Instrumental Variable Estimation of Error Component Models, Journal of Econometrics. 68: 29-51.

Bruni, Luigino and Lucio Stanca (2008). Watching Alone: Relational Goods, Television and Happiness, Journal of Economic Behavior \& Organization. 65(3): 506-528.

Carr, Alan (2004). Positive Psychology. London: Brunner-Routledge.

Cheng, Ya-Wei, Ovid J.L. Tzeng, Jean Decety, Toshiaki Imada and Jen-Chuen Hsieh (2006). Gender Differences in the Human Mirror system: a Magnetoencephalography Study, Neuroreport. 17(11): 1115-9.

Clark, Andrew E., Paul Frijters and Michael A. Shields (2006). Income and Happiness: Evidence, Explanations and Economic Implications, Paris Jourdan Sciences Economiques, Working Paper 2006-24.

Diwan, Romesh (2000). Relational Wealth and the Quality of Life, Journal of Socio - Economics. 29(4): 305-340.

Duesenberry, James S. (1949). Income, Saving and the Theory of Consumer Behaviour. Cambridge (Mass): Harvard University Press.

Easterlin, Richard A. (1974). Does Economic Growth Improve the Human Lot? In: Paul A. David and Melvin W. Reder (eds.), Nations and Households in Economic Growth: Essays in Honor of Moses Abramovitz. New York (NY): Academic Press, Inc: 89-125.

Ferrer-i-Carbonell, Ada (2005). Income and Well-being: an Empirical Analysis of the Comparison Income Effect, Journal of Public Economics. 89: 997-1019.

Frank, Robert H. (2005). Does Absolute Income Matter? In: Luigino Bruni and Pier Luigi Porta (eds.), Economics and Happiness. Oxford: Oxford University Press: 65-90.

Frey, Bruno S., Simon Luechinger and Alois Stutzer (2005). Valuing Public Goods: the Life Satisfaction Approach, Institute for Empirical Research in Economics University of Zurich Working Paper Series ISSN 1424-0459, Working Paper n. 184: 113-140.

Frey, Bruno S. and Alois Stutzer (2002a). Happiness and Economics. How the Economy and Institutions Affect Well-Being. Princeton (N. J.): Princeton University Press. 
Frey, Bruno S. and Alois Stutzer (2002b). What Can Economists Learn from Happiness Research?, Journal of Economic Literature. 40(2): 402-435.

Frey, Bruno S. and Alois Stutzer (2005). Does the Political Process Mitigate or Accentuate Individual Biases Due to Mispredicting Future Utility? In: E. McCaffery and J. Slemrod (eds). Behavioral Public Finance. New York (N.Y.): Russell Sage Foundation.

Frijters, Paul, Ingo Geishecker, Michael A. Shields and John P. Haisken-DeNew (2006). Can the Large Swings in Russian Life Satisfaction be Explained by Ups and Downs in Real Incomes? Scandinavian Journal of Economics. 108(3): 433-458.

Frijters, Paul, Michael A. Shields and John P. Haisken-DeNew (2004a). Money Does Matter! Evidence from Increasing Real Incomes in East Germany Following Reunification, American Economic Review. 94: 730-741.

Frijters, Paul, Michael A. Shields and John P. Haisken-DeNew (2004b). Changes in the Pattern and Determinants of Life Satisfaction in Germany Following Reunification, Journal of Human Resources. 39: 649-674.

Gardner, Jonathan and Andrew J. Oswald (2004). How is Mortality Affected by Money, Marriage and Stress? Journal of Health Economics. 23: 1181-1207.

Gui, Benedetto (1987). Éléments pour une Definition d' Economie Communautaire, Notes et Documents de l'Institut International Jacques Maritain 19/20.

Gui, Benedetto (2000). Beyond Transactions: on the Interpersonal Dimension of Economic Reality, Annals of Public and Cooperative Economics. 71(2): 139-169.

Gui, Benedetto and Robert Sugden (2005). Why Interpersonal Relations Matter for Economics, in: Benedetto Gui and Robert Sugden (eds.), Economics and Social Interactions, Accounting for Interpersonal Relations. Cambridge (Mass.): Cambridge University Press: 1-22.

Habermas, Jurgen (1990). Discourse Ethics: Notes on a Program of Philosophical Justification, in: Seyla Benhabib and Fred Dallmayr (eds.), The Communicative Ethics Controversy. Cambridge (Mass.): MIT Press: 60-110.

Hirshleifer, Jack (1978). Natural Economy Versus Political Economy, Journal of Social and Biological Structures. 1: 319-37.

Kasser, Tim (2002). The High Price of Materialism. Cambridge (Mass.): MIT Press.

Kahneman, Daniel (2003). Experienced Utility and Objective Happiness: A Moment-Based Approach, in: Isabelle Brocas and Juan D. Carrillo (eds.), The Psychology of Economic Decisions, Volume 1: Rationality and Well-Being. Oxford: Oxford University Press: 187-208.

Layard, Richard (2005). Happiness. Lessons from a New Science. London: Allen Lane.

Meier, Stephan and Alois Stutzer (2008). Is Volunteering Rewarding in Itself? Economica. 751: $39-59$.

Nelson, Julie (1996). The Masculine Mindset of Economic Analysis, The Chronicle of Higher Education. 42(42): B3.

Nussbaum, Martha (2001). The Fragility of Goodness. Cambridge (Mass.): Cambridge University Press.

Polanyi, Karl (1944). The Great Transformation. 2nd edition. Boston (Mass.): Beacon Press (2001).

Putnam, Robert (2000). Bowling Alone: the Collapse and Revival of American Community. New York: Simon\&Schuster.

Rasulo, Domenica, Kaare Christensen and Cecilia Tomassini (2005). The Influence of Social Relations on Mortality in Later Life: A Study on Elderly Danish Twins, The Gerontologist. 45: 601-608.

Rizzolatti, Giacomo, Leonardo Fogassi and Vittorio Gallese (2006). Mirrors in the Mind, Scientific American. 295(5): 54-61.

Schiff, Maurice (2002). Love Thy Neighbor: Trade, Migration and Social Capital, European Journal of Political Economy. 18(1): 87-107. 


\section{RELATIONAL GOODS, SOCIABILITY, AND HAPPINESS}

Sen, Amartya (1977). Rational Fools: A Critique of the Behavioral Foundations of Economic Theory, Philosophy and Public Affairs. 6: 314-344.

Sirgy, Joseph M. (1997). Materialism and Quality of Life, Social Indicators Research. 43(3): 227-260. Stern, Daniel N. (1985). The Interpersonal World of the Infant. New York: Basic Books.

Stutzer, Alois and Bruno S. Frey (2006). Does Marriage Make People Happy, or Do Happy People Get Married? Journal of Socio-Economics. 35(2): 326-347.

Sugden, Robert (2002). Beyond Sympathy and Empathy: Adam Smith's Concept of Fellow-Feeling, Economics and Philosophy. 18(1): 63-87.

Uhlaner, Carole J. (1989). Relational Goods and Participation: Incorporating Sociability into a Theory of Rational Action, Public Choice. 62: 253-285.

\section{SUMMARY}

This paper empirically investigates the impact of relational goods on individual life satisfaction. By relational goods we indicate the affective/expressive, non instrumental, side of interpersonal relationships. The homo oeconomicus view of human nature is questioned by the recent upsurge of empirical studies on the determinants of self declared happiness, that show that an increasing income does not always lead to more subjective well being (Easterlin's famous (1974) 'paradox of happiness'). The theoretical literature on relational goods has isolated various mechanisms which may induce an under-consumption and underproduction of relational goods. The hypothesis we test is that people with a more intense relational life are less affected by this 'relational poverty trap' and are therefore happier. Our findings does not disprove our hypothesis: relational goods turn out to have significant and positive effects on self declared life satisfaction, when other determinants isolated in the literature as important are taken into account and when the . inverse causality nexus i.e. from more happiness to a more intense relational life is also taken into account. Finally, we show that gender, age and education matter and in particular that the effects of sociability on happiness are stronger for women, older and less educated individuals. These findings can be useful in designing and evaluating public policies with a direct or indirect effect on the quality and quantity of relational goods. 